\title{
Prognosis of uveal melanoma based on race in 8100 patients: The 2015 Doyne Lecture
}

CL Shields ${ }^{1}$, S Kaliki 1,2, MN Cohen', PW Shields' M Furuta ${ }^{1}$ and JA Shields

\section{Abstract}

A retrospective, nonrandomized, interventional case series of 8100 patients with uveal melanoma were evaluated for melanoma-related metastasis based on patient race. The patient race was Caucasian $(n=7918,98 \%)$, Hispanic $(n=105,1 \%)$, Asian $(n=44,<1 \%)$, or African American $(n=33,<1 \%)$. On the basis of race (Caucasian, Hispanic, Asian, and African American), significant differences were noted in mean age at presentation $(58,48,44$, and 52 years; $P<0.001$ ), distance of posterior tumor margin to foveola $(5,5,6$, and $4 \mathrm{~mm} ; P<0.001)$, distance of posterior tumor margin to optic disc $(5,5,6$, and $4 \mathrm{~mm})(P<0.001)$, tumor base $(11,12$, 12 , and $13 \mathrm{~mm} ; P<0.001)$, tumor thickness (5.4, 7.1, 6.5, and 7.5 mm; $P<0.001)$, intraocular hemorrhage $(10,14,11$, and $24 \% ; P=0.02)$, and rupture of Bruch's membrane (20,27,39, and $36 \% ; P=0.001)$. On the basis of multivariate analysis, the rate of metastasis increased with increasing age $(P<0.001)$, ciliary body location $(P<0.001)$, increasing tumor base $(P<0.001)$, increasing tumor thickness $(P<0.001)$, pigmented tumor $(P=0.001)$, subretinal fluid $(P=0.001)$, intraocular hemorrhage $(P=0.045)$, and extraocular extension $(P=0.036)$. KaplanMeier estimates of metastasis at 3, 5, and 10 were 8,15 , and $25 \%$ in Caucasians; 13,13 , and $13 \%$ in Hispanics; 4,4 , and $36 \%$ in Asians; and 8, 8 , and $8 \%$ in African Americans. Compared with Caucasians, despite relative risk for metastasis of 0.31 for African Americans, 0.73 for Hispanics, and 1.42 for Asians, there was no statistical difference in metastasis, or death from uveal melanoma based on race. In summary, uveal melanoma showed similar prognosis for all races.

Eye (2015) 29, 1027-1035; doi:10.1038/eye.2015.51; published online 7 August 2015

\section{Introduction}

Cutaneous and uveal melanomas are classically found in the Caucasian population, although these malignancies can occur in African Americans, Hispanics, Asians, and Native Americans. Most reports on prevalence data and outcomes focus on Caucasians with little data on other races. The US Census Bureau reported that the Hispanic and Asian populations were the fastest growing racial/ ethnic groups in the USA in 2013 with over 54 million Hispanics and 19 million Asians, increasing at a rate of 2.1-2.9\% over 2012. ${ }^{1}$ With the rise in non-Caucasian populations, it is important to understand racial differences in diseases, particularly cancers.

Cormeier $e t a l^{2}$ reviewed the Surveillance, Epidemiology, and End Results (SEER) data from 1992-2002 for primary cutaneous melanoma in all races. In that cohort, they identified 48143 Caucasians (97\%), 932 Hispanics ( $2 \%), 251$ African Americans $(<1 \%)$, 52 American Indians $(<1 \%)$, and 294 Asians or Pacific Islanders (1\%). They observed that non-Caucasians were two to four times more likely to present with advanced stage IV cutaneous melanoma, compared with Caucasians. Furthermore, the 5-year survival was $90 \%$ for Caucasians and $72-81 \%$ for nonCaucasians. After adjustment for age, sex, and region, they found that non-Caucasians demonstrated a two- to threefold greater risk for melanoma-specific mortality compared with Caucasians.

Regarding uveal melanoma, there is little in the literature on this relatively rare malignancy based on patient race. ${ }^{3-10} \mathrm{We}$ have previously reviewed our 40-year experience with uveal melanoma in over 8000 patients relative to patient age at presentation, clinical features, tumor size, presence of melanocytosis, and classification. ${ }^{10-13}$ Herein, we explore this large cohort for the prevalence and outcomes of uveal melanoma based on patient race.
${ }^{1}$ Ocular Oncology Service, Wills Eye Hospital, Thomas Jefferson University, Philadelphia, PA, USA

${ }^{2}$ Dr Kaliki currently practices at the Ocular Oncology Service, L.V. Prasad Eye Institute, Hyderabad, India

Correspondence: CL Shields, Ocular Oncology Service, Suite 1440, Wills Eye Hospital, 840 Walnut Street, Philadelphia, PA 19107 USA

Tel: +1 215928 7161; Fax: +1215928 1140 . E-mail: carol.shields@ shieldsoncology.com

Received: 18 February 2015 Accepted: 24 February 2015 Published online:

7 August 2015

Presented in part as the 2015 Doyne Lecture at the Oxford Ophthalmological Congress, Oxford, England, 5 July 2015 to 8 July 2015. (CLS) 


\section{Methods}

This retrospective, interventional case series included all patients with uveal melanoma evaluated on the Ocular Oncology Service at Wills Eye Hospital between 25 August 1970 and 27 August 2008. The data were studied for clinical features and outcomes based on patient race (Caucasian, Hispanic, Asian, and African American). Institutional Review Board (IRB) approval was obtained.

The data were retrieved from the medical records and included age at diagnosis (years), gender (male, female), race (Caucasian, Hispanic, Asian, and African American), intraocular pressure ( $\mathrm{mm} \mathrm{Hg}$ ), location of tumor epicenter (iris, ciliary body, and choroid), quadrant location of tumor epicenter (superior, nasal, inferior, temporal, and macula), clock-hour location of the tumor epicenter (1 o'clock to 12 o'clock), anteroposterior location of tumor epicenter (iris, ciliary body, ora serrata to equator, equator to macula, macula), distance of posterior tumor margin to optic disc margin and foveola (mm), largest tumor basal dimension ( $\mathrm{mm}$ ) and thickness (mm), tumor configuration (dome, mushroom, plateau), color (pigmented, nonpigmented, mixed), Bruch membrane rupture, subretinal fluid, intraocular hemorrhage, and extraocular extension. Tumor basal diameter was measured by indirect ophthalmoscopy and tumor thickness by ocular ultrasonography. All findings were documented with large fundus drawing, fundus photography, fluorescein angiography, and ultrasonography.

The tumor management was recorded. Systemic monitoring and screening for metastasis was performed by a medical oncologist with twice-a-year physical examination and liver function tests (lactate dehydrogenase, alkaline phosphatase, alanine aminotransferase, and aspartate aminotransferase), oncea-year liver imaging (magnetic resonance imaging, computed tomography scan, or ultrasonography), and chest imaging (chest radiograph or computed tomography). The date and interval to systemic metastasis were recorded. The date, cause, and interval to death as revealed by the family or doctors were recorded.

The related features and outcomes (melanoma-related metastasis and death) were then statistically analyzed based on race (Caucasian, Hispanic, Asian, and African American).

\section{Statistical analysis}

Data were summarized as number and percentages for the categorical variables and as mean, median, and range for those measured on a continuous scale. The summaries of each feature were presented based on race. The categorical demographic characteristics and clinical features were compared using $\chi^{2}$-test between Caucasian, Hispanic, Asian, and African American race and the paired comparisons were performed using Fisher's exact test and $\chi^{2}$-test as appropriate. The characteristics and features measured on continuous scale were compared using analysis of variance followed by post hoc comparisons using Bonferroni correction.

Kaplan-Meier (KM) analysis was performed to estimate the cumulative probability of metastasis and death at 1, 3, 5, 10, 15, 20, and 25 years of follow-up among Caucasian, Hispanic, Asian, and African American race. The factors predictive of metastasis and death due to metastasis were analyzed using Cox proportional hazard model in all patients and also specifically in each race. The factors found significant on univariable analysis at 5\% level of significance were considered for multivariable analysis using forward stepwise method. The factors significant at 0.05 levels on multivariable analysis were reported. The hazard ratios were accompanied by its $95 \%$ confidence intervals.

\section{Results}

Of 8100 patients with uveal melanoma managed on the Ocular Oncology Service, Wills Eye Hospital, the patient race (listed in order) included 7918 (98\%) Caucasians, 105

Table 1 Prognosis of uveal melanoma based on race in 8100 patients: demographics

\begin{tabular}{|c|c|c|c|c|c|c|}
\hline Feature & $\begin{array}{c}\text { Any race } \\
(\mathrm{n}=8100) \\
n(\%)\end{array}$ & $\begin{array}{c}\text { Caucasian }^{\mathrm{a}} \\
(\mathrm{n}=7918) \\
n(\%)\end{array}$ & $\begin{array}{c}\text { Hispanic } \\
(\mathrm{n}=105) \\
n(\%)\end{array}$ & $\begin{array}{c}\text { Asian } \\
(\mathrm{n}=44) \\
n(\%)\end{array}$ & $\begin{array}{c}\text { African American } \\
(\mathrm{n}=33) \\
n(\%)\end{array}$ & P-value ${ }^{\mathrm{b}}$ \\
\hline $\begin{array}{l}\text { Age (years) mean (median, range) } \\
\text { Gender }(\mathrm{n}=8100)\end{array}$ & $58(59,3-99)$ & $58(59,3-99)$ & $48(48,6-85)$ & $44(43,19-78)$ & $52(52,25-83)$ & $\begin{array}{c}<0.001^{\mathrm{c}} \\
0.430\end{array}$ \\
\hline $\begin{array}{l}\text { Male } \\
\text { Female }\end{array}$ & $\begin{array}{l}4093(51) \\
4007(49)\end{array}$ & $\begin{array}{l}3990(50) \\
3928(50)\end{array}$ & $\begin{array}{l}59(56) \\
46(44)\end{array}$ & $\begin{array}{l}25(57) \\
19(43)\end{array}$ & $\begin{array}{l}19(58) \\
14(42)\end{array}$ & \\
\hline $\begin{array}{l}\text { Eye }(\mathrm{n}=8100) \\
\text { Right } \\
\text { Left }\end{array}$ & $\begin{array}{l}3961(49) \\
4139(51)\end{array}$ & $\begin{array}{l}3869(49) \\
4049(51)\end{array}$ & $\begin{array}{l}49(47) \\
56(53)\end{array}$ & $\begin{array}{l}23(52) \\
21(48)\end{array}$ & $\begin{array}{l}20(61) \\
13(39)\end{array}$ & 0.527 \\
\hline
\end{tabular}

${ }^{\mathrm{a}}$ Reference variable. ${ }^{\mathrm{b}} \chi^{2}$-test. ${ }^{\mathrm{c}}$ One-way analysis of variance. 
Table 2 Prognosis of uveal melanoma based on race in 8100 patients: tumor features

\begin{tabular}{|c|c|c|c|c|c|c|}
\hline Feature & $\begin{array}{c}\text { Any race } \\
(\mathrm{n}=8100) \\
n(\%)\end{array}$ & $\begin{array}{c}\text { Caucasian } \\
(\mathrm{n}=7918) \\
n(\%)\end{array}$ & $\begin{array}{c}\text { Hispanic } \\
(\mathrm{n}=105) \\
n(\%)\end{array}$ & $\begin{array}{c}\text { Asian } \\
(\mathrm{n}=44) \\
n(\%)\end{array}$ & $\begin{array}{c}\text { African American } \\
(\mathrm{n}=33) \\
n(\%)\end{array}$ & P-value ${ }^{\mathrm{a}}$ \\
\hline $\begin{array}{l}\text { Quadrantic location of tumor epicenter } \\
(\mathrm{n}=8081)\end{array}$ & & & & & & 0.503 \\
\hline Superior & $1770(22)$ & $1722(22)$ & $30(29)$ & $10(23)$ & $8(25)$ & \\
\hline Nasal & $1689(21)$ & $1646(21)$ & $25(24)$ & $10(23)$ & $8(25)$ & \\
\hline Inferior & $1762(22)$ & $1724(22)$ & $21(20)$ & $11(25)$ & $6(19)$ & \\
\hline Temporal & $2243(28)$ & $2201(28)$ & $25(24)$ & $12(27)$ & $5(16)$ & \\
\hline Macula & $358(4)$ & $353(4)$ & $1(1)$ & $1(2)$ & $3(9)$ & \\
\hline Diffuse & $259(3)$ & $254(3)$ & $3(3)$ & $0(0)$ & $2(6)$ & \\
\hline $\begin{array}{l}\text { Clock hour of tumor epicenter } \\
(\mathrm{n}=8080)\end{array}$ & & & & & & 0.251 \\
\hline 1 & $504(6)$ & $488(6)$ & $11(10)$ & $3(7)$ & $2(6)$ & \\
\hline 2 & $589(7)$ & $578(7)$ & $4(4)$ & $3(7)$ & $4(13)$ & \\
\hline 3 & $904(11)$ & $885(11)$ & $13(12)$ & $4(9)$ & $2(6)$ & \\
\hline 4 & $615(8)$ & $601(8)$ & $7(7)$ & $6(14)$ & $1(3)$ & \\
\hline 5 & $591(7)$ & $582(7)$ & $4(4)$ & $3(7)$ & $2(6)$ & \\
\hline 6 & $651(8)$ & $630(8)$ & $14(13)$ & $5(11)$ & $2(6)$ & \\
\hline 7 & $575(7)$ & $567(7)$ & $4(4)$ & $2(5)$ & $2(6)$ & \\
\hline 8 & $664(8)$ & $646(8)$ & $9(9)$ & $5(11)$ & $4(13)$ & \\
\hline 9 & $896(11)$ & $881(11)$ & $12(11)$ & $2(5)$ & $1(3)$ & \\
\hline 10 & $596(7)$ & $584(7)$ & $6(6)$ & $3(7)$ & $3(9)$ & \\
\hline 11 & $561(7)$ & $547(7)$ & $12(11)$ & $1(2)$ & $1(3)$ & \\
\hline 12 & $686(8)$ & $669(8)$ & $7(7)$ & $6(14)$ & $4(13)$ & \\
\hline Diffuse & $248(3)$ & $241(3)$ & $2(2)$ & $1(2)$ & $4(13)$ & \\
\hline $\begin{array}{l}\text { Anteroposterior tumor epicenter } \\
(\mathrm{n}=8085)\end{array}$ & & & & & & 0.042 \\
\hline Iris & $317(4)$ & $312(4)$ & $2(2)$ & $2(5)$ & $1(3)$ & \\
\hline Ciliary body & $501(6)$ & $481(6)$ & $14(13)$ & $5(11)$ & $1(3)$ & \\
\hline Ora serrata to equator & $1207(15)$ & $1170(15)$ & $19(18)$ & $11(25)$ & $7(22)$ & \\
\hline Equator to macula & $5702(71)$ & $5588(71)$ & $67(64)$ & $26(59)$ & $21(66)$ & \\
\hline Macula & $358(4)$ & $353(4)$ & $3(3)$ & $0(0)$ & $2(6)$ & \\
\hline Anterior tumor margin $(\mathrm{n}=8085)$ & & & & & & 0.092 \\
\hline Iris & $874(11)$ & $843(11)$ & $17(16)$ & $10(23)$ & $4(13)$ & \\
\hline Ciliary body & 1502 (19) & $1463(19)$ & $26(25)$ & $7(16)$ & $6(19)$ & \\
\hline Ora serrata to equator & $2247(28)$ & $2195(28)$ & $26(25)$ & $15(34)$ & $11(34)$ & \\
\hline Equator to macula & $3368(42)$ & $3309(42)$ & $36(34)$ & $12(27)$ & $11(34)$ & \\
\hline Macula & $94(1)$ & $94(1)$ & $0(0)$ & $0(0)$ & $0(0)$ & \\
\hline Posterior tumor margin $(\mathrm{n}=8086)$ & & & & & & 0.602 \\
\hline Iris & $255(3)$ & $251(3)$ & $2(2)$ & $2(5)$ & $0(0)$ & \\
\hline Ciliary body & $172(2)$ & $164(2)$ & $4(4)$ & $2(5)$ & $2(6))$ & \\
\hline Ora serrata to equator & $282(3)$ & $274(3)$ & $5(5)$ & $2(5)$ & $1(3)$ & \\
\hline Equator to macula & $3988(49)$ & $3896(49)$ & $50(48)$ & $25(57)$ & $17(53)$ & \\
\hline Macula & $3389(42)$ & $3320(42)$ & $44(42)$ & $13(30)$ & $12(38)$ & \\
\hline $\begin{array}{l}\text { Distance to foveola (mm) } \\
\text { mean (median, range) }\end{array}$ & $5(3,0-25)$ & $5(3,0-25)$ & $5(4,0-22)$ & $6(5,0-21)$ & $4(3,0-21)$ & $<0.001^{\mathrm{b}}$ \\
\hline $\begin{array}{l}\text { Distance to optic disc (mm) } \\
\text { mean (median, range) }\end{array}$ & $5(4,0-25)$ & $5(4,0-25)$ & $5(4,0-22)$ & $6(6,0-19)$ & $4(2,0-21)$ & $<0.001^{\mathrm{b}}$ \\
\hline $\begin{array}{l}\text { Tumor base }(\mathrm{mm}) \\
\text { mean (median, range) }\end{array}$ & $11(11,1-33)$ & $11(11,1-33)$ & $12(12,5-24)$ & $12(12,5-23)$ & $13(13,5-24)$ & $<0.001^{\mathrm{b}}$ \\
\hline $\begin{array}{l}\text { Tumor thickness }(\mathrm{mm}) \\
\text { mean (median, range) }\end{array}$ & $5.5(4.5,1-24)$ & $5.4(4.5,1-24)$ & $7.1(7.0,1.8-18)$ & $6.5(6.5,1.5-15)$ & $7.5(7.0,2.6-18.3)$ & $<0.001^{\mathrm{b}}$ \\
\hline Tumor configuration $(\mathrm{n}=8051)$ & & & & & & $<0.001$ \\
\hline Plateau/diffuse & $471(6)$ & $467(6)$ & $2(2)$ & $1(2)$ & $1(3)$ & \\
\hline Dome & $6086(76)$ & $5966(76)$ & $75(71)$ & $24(56)$ & $21(64)$ & \\
\hline Mushroom & $1494(19)$ & $1437(18)$ & $28(27)$ & $18(42)$ & 11 (33) & \\
\hline
\end{tabular}


Table 2. (Continued)

\begin{tabular}{|c|c|c|c|c|c|c|}
\hline Feature & $\begin{array}{c}\text { Any race } \\
(\mathrm{n}=8100) \\
n(\%)\end{array}$ & $\begin{array}{c}\text { Caucasian } \\
(\mathrm{n}=7918) \\
n(\%)\end{array}$ & $\begin{array}{c}\text { Hispanic } \\
(\mathrm{n}=105) \\
n(\%)\end{array}$ & $\begin{array}{c}\text { Asian } \\
(\mathrm{n}=44) \\
n(\%)\end{array}$ & $\begin{array}{c}\text { African American } \\
(\mathrm{n}=33) \\
n(\%)\end{array}$ & P-value ${ }^{\mathrm{a}}$ \\
\hline Color $(\mathrm{n}=8076)$ & & & & & & 0.078 \\
\hline Pigmented & $4417(55)$ & $4298(54)$ & $68(65)$ & $29(67)$ & $22(69)$ & \\
\hline Nonpigmented & $1229(15)$ & $1204(15)$ & $14(13)$ & $6(14)$ & $5(16)$ & \\
\hline Mixed & $2430(30)$ & $2394(30)$ & $23(22)$ & $8(19)$ & $5(16)$ & \\
\hline \multicolumn{7}{|l|}{ Other features $(\mathrm{n}=8100)$} \\
\hline Subretinal fluid & $5686(70)$ & $5561(70)$ & $73(70)$ & $25(57)$ & $27(82)$ & 0.075 \\
\hline Intraocular hemorrhage & $825(10)$ & $797(10)$ & $15(14)$ & $5(11)$ & $8(24)$ & 0.020 \\
\hline Rupture of Bruch's membrane & $1674(21)$ & $1617(20)$ & $28(27)$ & $17(39)$ & $12(36)$ & 0.001 \\
\hline Extraocular extension & $223(3)$ & $217(3)$ & $5(5)$ & $1(2)$ & $0(0)$ & 0.471 \\
\hline
\end{tabular}

${ }^{\mathrm{a}} \chi^{2}$-test. ${ }^{\mathrm{b}}$ One-way Analysis of Variance.

(1\%) Hispanics, $44(<1 \%)$ Asians, and 33 (<1\%) African Americans. The patient demographics are listed in Table 1. On the basis of race (Caucasians, Hispanics, Asians, and African Americans), a significant difference was noted in mean age at presentation $(58,48,44$, and 52 years; $P<0.001)$.

The tumor features are listed in Table 2. Significant differences were detected in distance of melanoma posterior margin to foveola $(5,5,6$, and $4 \mathrm{~mm}$; $P<0.001)$, distance of posterior tumor margin to optic disc $(5,5,6$, and $4 \mathrm{~mm} ; P<0.001)$, tumor base $(11,12,12$, and $13 \mathrm{~mm}$; $P<0.001)$, tumor thickness $(5.4,7.1,6.5$, and $7.5 \mathrm{~mm}$; $P<0.001)$, intraocular hemorrhage $(10,14,11$, and $24 \%$; $P=0.02)$, rupture of Bruch's membrane $(20,27,39$, and $36 \%)(P=0.001$; Figures 1 and 2$)$.

KM estimates for metastasis and death are listed in Table 3. Estimates at 3, 5, 10, 15, 20, and 25 years were 8, $15,25,31,36$, and $45 \%$ for metastasis and 5, 9, 14, 16, 19, and $23 \%$ for death in Caucasians. KM estimates at 10 years for melanoma-related metastasis were $12 \%$ for Hispanics, 36\% for Asians, and 8\% for African Americans. KM estimates at 10 years for melanoma-related death were $6 \%$ for Hispanics, $0 \%$ for Asians, and $0 \%$ for African Americans. There was no statistical difference in metastasis or death comparing the Caucasian population to the Hispanic, Asian, or African American populations. The hazard ratio for metastasis, relative to the Caucasian group, was 0.73 for Hispanics, 1.42 for Asians, and 0.31 for African Americans.

Multivariate analyses for factors predictive of metastasis and death in the entire group and specifically for each race is listed in Table 4. Overall, for all races, based on multivariate analysis, the rate of metastasis increased with increasing age $(P<0.001)$, ciliary body location $(P<0.001)$, increasing tumor base $(P<0.001)$, increasing tumor thickness $(P<0.001)$, pigmented tumors $(P=0.001)$, subretinal fluid $(P=0.001)$, intraocular hemorrhage $(P=0.045)$, and extraocular extension $(P=0.036)$. Based on multivariate analysis, the factors determining metastasis in Caucasians were increasing age $(P<0.001)$, ciliary body location $(P<0.001)$, increasing tumor base $(P<0.001)$, increasing tumor thickness $(P<0.001)$, pigmented tumors $(P=0.001)$, subretinal fluid $(P=0.001)$, intraocular hemorrhage $(P=0.027)$, and extraocular extension $(P=0.035)$. The multivariate factor for metastasis in Hispanics was increasing tumor basal dimension $(P=0.039)$. There were no significant factors for metastasis in Asians or African Americans.

\section{Discussion}

Over the past several decades, cutaneous melanoma incidence has increased more rapidly that any other human cancer, with a doubled incidence in Caucasians. ${ }^{14}$ For Caucasians, it is estimated that 1 in 41 men and 1 in 61 women will experience cutaneous melanoma during their lifetime. ${ }^{14}$ Most of the literature on cutaneous melanoma addresses this disease in Caucasians (Whites) due to its overwhelming prevalence in that race. In regions of high sun exposure, such as Florida, Hu et al further emphasized the disparity in cutaneous melanoma with $96 \%$ in non-Hispanic Whites (Caucasians), 3\% in Hispanics, and $<1 \%$ in non-Hispanic Blacks. ${ }^{15}$ They commented that the lower incidence of melanoma in nonCaucasians was attributed to the protective effects of skin and eye pigmentation, but recognized that Hispanics were demonstrating a rising incidence, along with Caucasians, and sun-protective measures for all races were warranted. ${ }^{15}$ Rouhani et al ${ }^{16}$ noted the cutaneous melanoma incidence in Hispanic males in Florida was $20 \%$ higher than their male non-Floridian counterparts in the SEER database. They suggested that these previously 

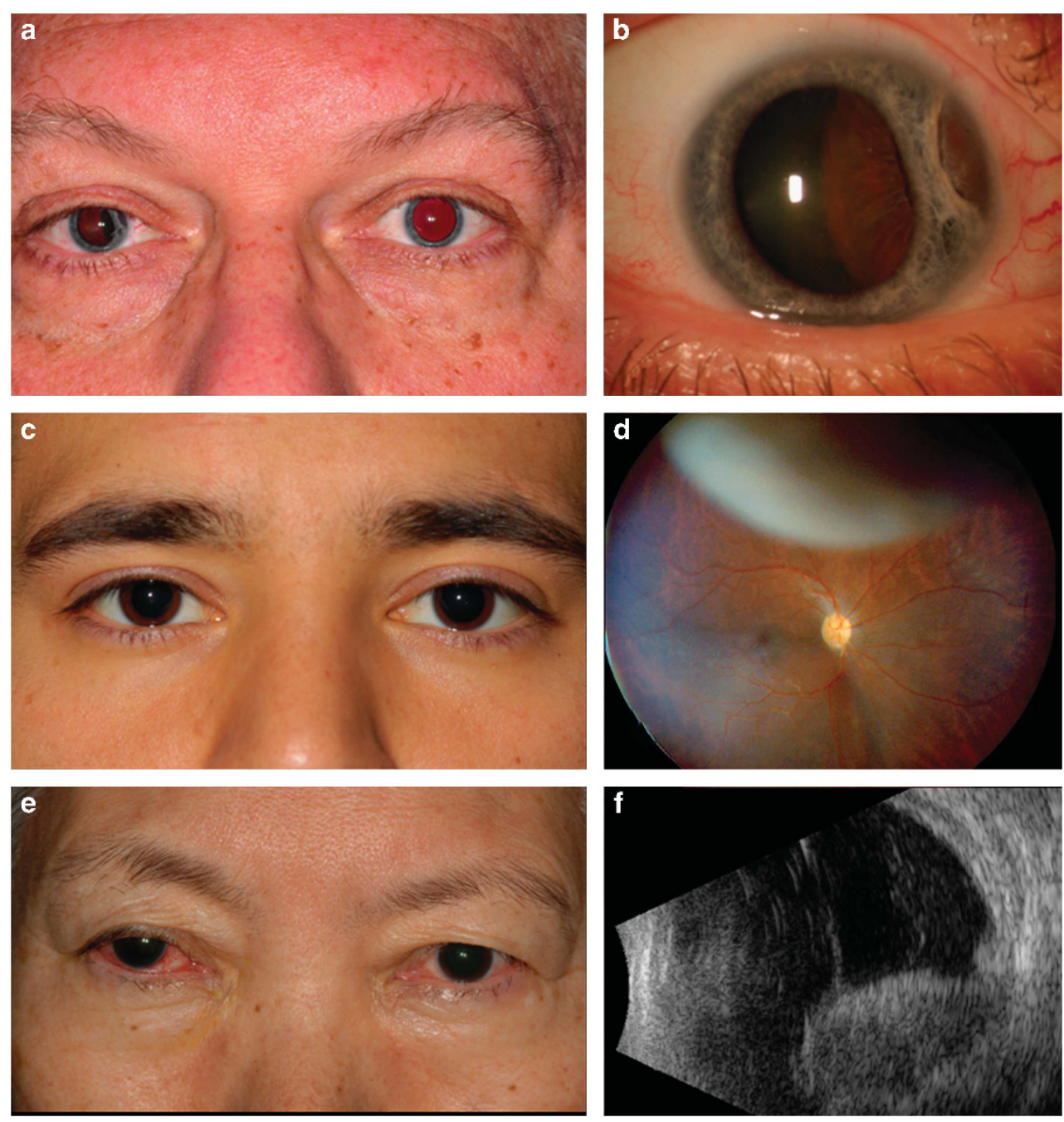

Figure 1 Uveal melanoma in various races including Caucasian (a and b); Hispanic (c and d); and Asian (e and f) persons.

understudied racial groups could pose an emerging public health concern.

There have been a few studies to assess features and prognosis of uveal melanoma in non-Caucasians. ${ }^{3-10}$ Margo et $a l^{5}$ evaluated enucleated eyes with uveal melanoma in the Florida Cancer Data System between 1981 and 1993, stratified by race, and noted 814 (94\%) Caucasians, 47 (5\%) Hispanics, and 4 (<1\%) African Americans. They observed that Caucasian men had a $72-$ fold greater risk for uveal melanoma compared to African American men and Caucasian women had 22-fold risk compared with African American women. ${ }^{5}$ They concluded that uveal melanoma in African American is exceptionally low and they speculated the reasons include increased pigmentation and possible cultural, environmental, or socioeconomic factors.

The population-based incidence of uveal melanoma has been studied using the Surveillance, Epidemiology, and End Results (SEER) database. In 2003, Singh and
Topham ${ }^{7}$ analyzed the SEER database from 1973 to 1997. There were 2438 Whites (98\%), 17 Blacks (<1\%), 5 Asians $(<1 \%)$, and 33 others $(2 \%)$, with a White:Black ratio of $143: 1$. The overall annual survival varied from 76 to $84 \%$ over the 20-year period, but was not analyzed specifically by race. ${ }^{7} \mathrm{Hu}$ et $a l^{9}$ studied the incidence of uveal melanoma in various races using the SEER database over an 8-year period from 1992 to 2000. The age-adjusted incidence (per million population) of uveal melanoma was 0.3 for Blacks, 0.4 for Asians, 1.7 for Hispanics, and 6 for non-Hispanic Whites. ${ }^{9}$ The difference in incidence was statistically significant, except for Black versus Asian. Compared with Black patients, the relative risk for melanoma development was 1.2 for Asians, 5.4 for Hispanics, and 19.2 for non-Hispanic Whites. ${ }^{9}$ Clinical features and prognosis were not provided in that analysis.

Clinical features and outcomes of uveal melanoma in specific races have been explored. ${ }^{3,4,6,8}$ In 1982, Kuo et al ${ }^{3}$ reviewed results in 65 Chinese patients with uveal 

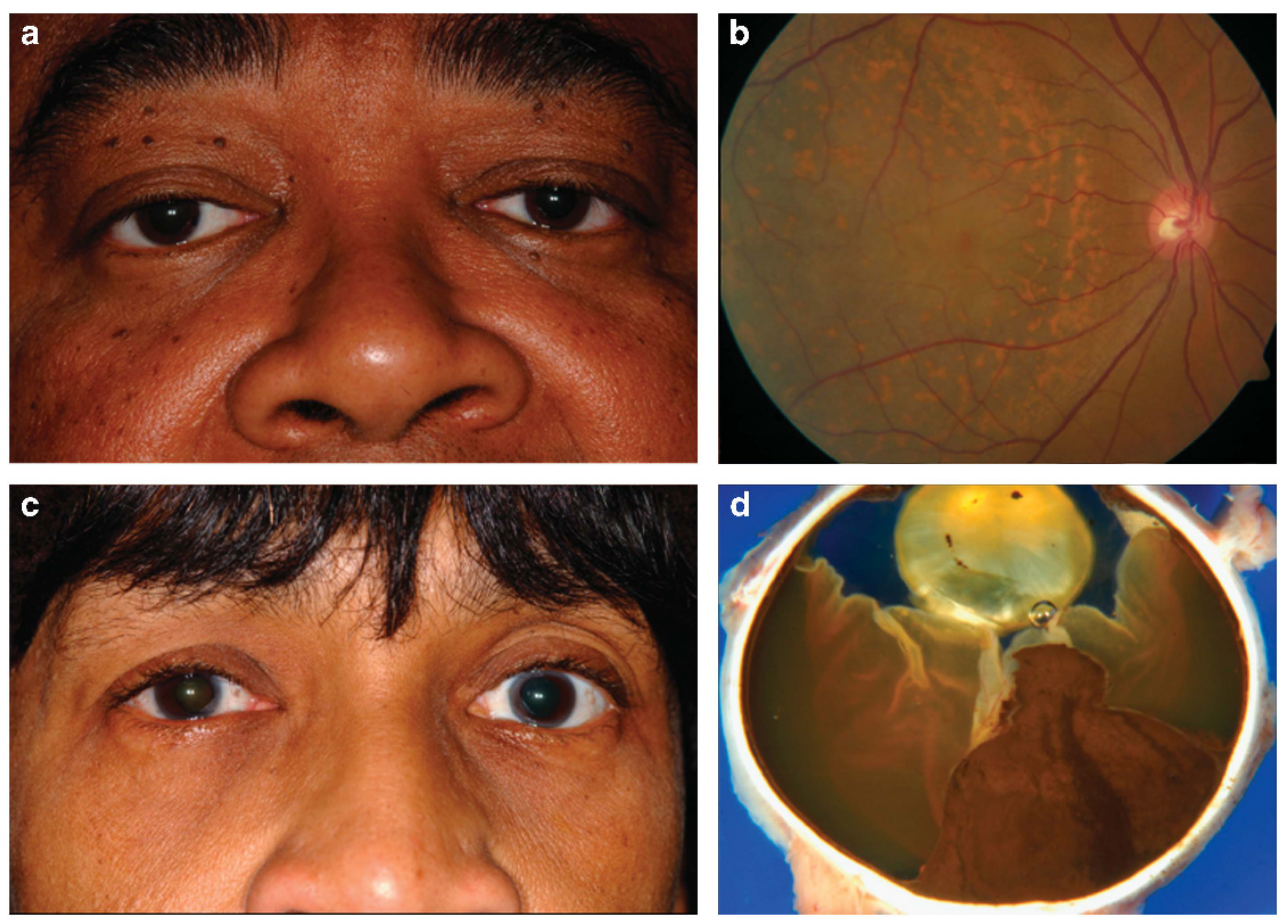

Figure 2 Uveal melanoma in African American patients (a-d) showing diffuse melanoma (a and b); and mushroom shaped melanoma (c and d).

melanoma and noted younger age at presentation compared with Caucasians from the USA. In 1984, Margo and McLean ${ }^{4}$ determined that death rates from uveal melanoma were equivalent in 39 Blacks versus 3339 Whites, based on data from the Armed Forces Institute of Pathology. However, they noted that Blacks were more likely to have advanced findings like secondary glaucoma, inflammation, and histopathologic evidence of heavy pigmentation and necrosis. Biswas et al evaluated 103 eyes with uveal melanoma in Asian Indians and provided comparison with other ethnic groups, noting that melanoma in Asian Indians tends to occur in younger patients (mean age 46 years) and with greater diameter (mean basal diameter $13 \mathrm{~mm}$ ) compared to Caucasians. ${ }^{8}$ In 1995, Philpotts et al evaluated 10 Black patients with uveal melanoma, highlighting the rarity of this condition in Blacks. 6

In our series of 8100 patients with uveal melanoma, there were 7918 (98\%) Caucasians, 105 (1\%) Hispanics, 44 $(<1 \%)$ Asians, and $33(<1 \%)$ African Americans. The ratio was 240 Caucasians: 3 Hispanics: 1 Asian: 1 African American. Our goal was to investigate the clinical features and prognosis of uveal melanoma in the Caucasian versus non-Caucasian populations. We found that Caucasians presented with uveal melanoma at a older age (58 years) compared to non-Caucasians (44-52 years; $P<0.001$; Table 1). Clinically, Caucasians showed melanoma with significantly more posterior location $(P=0.04)$, closer to the foveola $(P<0.001)$ and optic disc $(P<0.001)$, with smaller basal dimension $(P<0.001)$ and thickness $(P<0.001)$, and with less Bruch's membrane rupture $(P=0.0010$ and less intraocular hemorrhage $(P=0.02)$, compared to non-Caucasians. Regarding prognosis in this large cohort, 10 -year metastatic rate was $25 \%$ in Caucasians, $12 \%$ in Hispanics, 36\% in Asians, and 8\% in African Americans, but the differences were not statistically significant. Similar to cutaneous melanoma, non-Caucasians demonstrated larger and more advanced tumors. Unlike cutaneous melanoma, despite larger melanoma in non-Caucasians, there was no difference in prognosis.

Limitations of this data analysis included the small cohort size for the non-Caucasian groups, the retrospective nature of data collection, and the possibility for incomplete follow-up in patients with metastatic events. With rare malignancies, such as uveal melanoma, these factors can reduce the power of outcomes. Despite this, we have a large cohort of 8100 patients over 40 years that were analyzed. It is possible that there could be a protective effect of background choroidal pigment, genetic alterations, or immunologic mechanisms that could have lead to similar outcomes despite larger tumors in non-Caucasians. On the basis of our results, uveal melanoma prognosis does not differ based on race. 


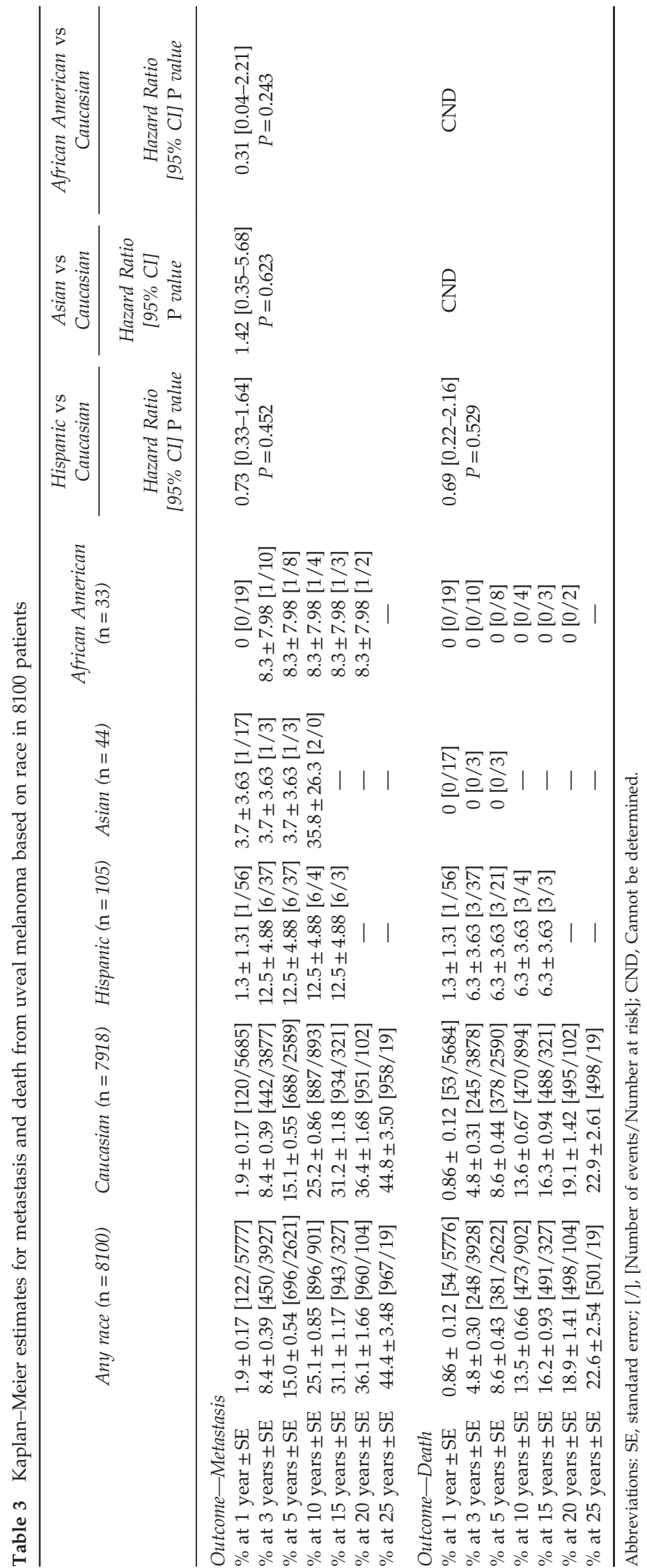


Table 4 Factors predictive of metastasis and death from uveal melanoma based on race in 8100 patients: multivariate analysis

\begin{tabular}{|c|c|c|c|c|c|c|}
\hline \multirow{2}{*}{$\begin{array}{l}\text { Feature } \\
\text { Multivariate analysis }\end{array}$} & \multicolumn{3}{|c|}{ Metastasis } & \multicolumn{3}{|c|}{ Death } \\
\hline & P-value & Hazard ratio & $95 \% C I$ & P-value & Hazard ratio & $95 \% \mathrm{CI}$ \\
\hline \multicolumn{7}{|l|}{ All races $(\mathrm{n}=8100)$} \\
\hline Age (years) & $<0.001$ & $1.13 a$ & $1.08-1.18$ & $<0.001$ & $1.17 \mathrm{a}$ & $1.10-1.25$ \\
\hline \multicolumn{7}{|l|}{ Anterior tumor margin } \\
\hline Iris vs Equator to macula ${ }^{b}$ & 0.040 & 1.33 & $1.01-1.75$ & - & - & - \\
\hline Ciliary body vs Equator to maculab & $<0.001$ & 1.70 & $1.39-2.08$ & $<0.001$ & 1.99 & $1.51-2.61$ \\
\hline Tumor base $(\mathrm{mm})$ & $<0.001$ & $1.14 \mathrm{~b}$ & $1.11-1.16$ & $<0.001$ & $1.13 b$ & $1.10-1.16$ \\
\hline Tumor thickness (mm) & $<0.001$ & $1.06 \mathrm{~b}$ & $1.04-1.09$ & $<0.001$ & $1.07 \mathrm{~b}$ & $1.03-1.11$ \\
\hline \multicolumn{7}{|l|}{ Color } \\
\hline Pigmented vs Non-pigmented ${ }^{\mathrm{b}}$ & 0.001 & 1.43 & $1.16-1.75$ & 0.030 & 1.37 & $1.03-1.81$ \\
\hline \multicolumn{7}{|l|}{ Other features } \\
\hline Subretinal fluid & 0.001 & 1.32 & $1.12-1.55$ & 0.042 & 1.25 & $1.01-1.56$ \\
\hline Intraocular hemorrhage & 0.045 & 1.21 & $1.01-1.47$ & - & - & - \\
\hline Extraocular extension & 0.036 & 1.41 & $1.02-1.95$ & - & - & - \\
\hline \multicolumn{7}{|l|}{ Caucasians $(\mathrm{n}=7918)$} \\
\hline Age (years) & $<0.001$ & $1.13 \mathrm{a}$ & $1.08-1.18$ & $<0.001$ & $1.16 \mathrm{a}$ & $1.09-1.24$ \\
\hline \multicolumn{7}{|l|}{ Anterior tumor margin } \\
\hline Iris vs Equator to macula ${ }^{b}$ & 0.037 & 1.34 & $1.02-1.76$ & - & - & - \\
\hline Ciliary body $v s$ Equator to maculab & $<0.001$ & 1.71 & $1.40-2.09$ & $<0.001$ & 1.88 & $1.44-2.46$ \\
\hline Tumor base $(\mathrm{mm})$ & $<0.001$ & $1.13 b$ & $1.11-1.16$ & $<0.001$ & $1.13 b$ & $1.10-1.16$ \\
\hline Tumor thickness (mm) & $<0.001$ & $1.06 \mathrm{~b}$ & $1.04-1.09$ & $<0.001$ & $1.08 \mathrm{~b}$ & $1.04-1.11$ \\
\hline \multicolumn{7}{|l|}{ Color } \\
\hline Pigmented vs Non-pigmented ${ }^{\mathrm{b}}$ & 0.001 & 1.44 & $1.17-1.77$ & 0.029 & 1.37 & $1.03-1.83$ \\
\hline \multicolumn{7}{|l|}{ Other features } \\
\hline Subretinal fluid & 0.001 & 1.30 & $1.11-1.53$ & - & - & - \\
\hline Intraocular hemorrhage & 0.027 & 1.24 & $1.02-1.50$ & - & - & - \\
\hline Extraocular extension & 0.035 & 1.42 & $1.03-1.96$ & - & - & - \\
\hline \multicolumn{7}{|l|}{ Hispanic $(\mathrm{n}=105)$} \\
\hline Tumor base (mm) & 0.039 & $1.25 b$ & $1.01-1.54$ & - & - & - \\
\hline
\end{tabular}

Abbreviation: CI, confidence interval. aMultivariable Cox proportion hazard model using forward stepwise method. There were no significant factors predictive of metastasis and death in Asian and African American, potentially related to small sample size. a, per 10-year increase; $b$, per 1-mm increase.

${ }^{\mathrm{b}}$ Reference category.

In summary, uveal melanoma most often occurs in Caucasians $(98 \%)$, with rare detection in non-Caucasians (2\%). Non-Caucasians demonstrate larger, more hemorrhagic, and more peripheral tumors, but outcomes of metastasis were similar to Caucasians. Ophthalmologists should recognize that uveal melanoma can occur in persons of any race and can be life threatening.

\section{Conflict of interest}

The authors declare no conflict of interest.

\section{Acknowledgements}

Support provided by a Wills Innovation Grant, Philadelphia, PA, USA (CLS MNC, JAS), Eye Tumor Research Foundation, Philadelphia, PA, USA (CLS, JAS). Statistical analysis provided by Rishita Nutheti, Ph.D., Hyderabad, India. The funders had no role in the design and conduct of the study, in the collection, analysis, and interpretation of the data, and in the preparation, review or approval of the manuscript. CLS, M.D. has had full access to all the data in the study and takes responsibility for the integrity of the data and the accuracy of the data analysis.

\section{References}

1 Brown A. US Hispanic and Asian populations growing, but for different reasons. Pew Research Center Fact Tank 2014. http:/ / www.pewresearch.org/fact-tank/2014/06/26/ u-s-hispanic-and-asian-populations-growing-but-fordifferent-reasons/. Accessed on 4 October 2014.

2 Cormier JN, Xing Y, Ding M, Lee JE, Mansfield PF, Gershenwald JE, Ross MI, Du XL. Ethnic differences among patients with cutaneous melanoma. Arch Intern Med 2006; 166: 1907-1914.

3 Kuo PK, Puliafito CA, Wang KM, Liu HS, Wu BF. Uveal melanoma in China. Int Ophthalmol Clin 1982; 22: 57-71. 
4 Margo CE, McLean IW. Malignant melanoma of the choroid and ciliary body in black patients. Arch Ophthalmol 1984; 102: 77-79.

5 Margo CE, Mulla Z, Billiris K. Incidence of surgically treated uveal melanoma by race and ethnicity. Ophthalmology 1998; 105: 1087-1090.

6 Phillpotts BA, Sanders RJ, Shields JA, Griffiths JD, Augsburger JA, Shields CL. Uveal melanomas in Black patients - A case series and comparative review. J Natl Med Assoc 1995; 87: 709-714.

7 Singh AD, Topham A. Survival rates with uveal melanoma in the United States: 1973-1997. Ophthalmology 2003; 110:, 962-965.

8 Biswas J, Kabra S, Krishnakumar S, Shanmugan M. Clinical and histopathological characteristics of uveal melanoma in Asian Indians. A study of 103 patients. Indian J Ophthalmol 2004; 52: 41-44.

9 Hu DN, Yu GP, McCormick SA, Schneider S, Finger PT. Population-based incidence of uveal melanoma in various races and ethnic groups. Am J Ophthalmol 2005; 140: 612-617.

10 Shields CL, Kaliki S, Furuta M, Mashayekhi A, Shields JA. Clinical spectrum and prognosis of uveal melanoma based on age at presentation in 8,033 cases. Retina 2012; 32(7): 1363-1372.
11 Shields CL, Furuta M, Thangappan A, Nagori S, Mashayekhi A, Lally DR et al. Metastasis of uveal melanoma millimeter-by-millimeter in 8033 consecutive eyes. Arch Ophthalmol 2009; 127(8): 989-998.

12 Shields CL, Kaliki S, Livesey M, Walker B, Garoon R, Bucci $\mathrm{M}$ et al. Association of ocular and oculodermal melanocytosis with rate of uveal melanoma metastasis. analysis of 7872 consecutive eyes. JAMA Ophthalmol 2013; 131(8): 993-1003.

13 Shields CL, Kaliki S, Furuta M, Fulco E, Alarcon C, Shields JA. American Joint Committee on Cancer classification of posterior uveal melanoma (tumor size category) predicts prognosis in 7731 patients. Ophthalmology 2013; 120(10): 2066-2071.

14 Jemal A, Siegel R, Ward E, Hao Y, Xu J, Murray T, Thun MJ. Cancer statistics, 2008. CA Cancer J Clin 2008; 58(2): 71-96.

15 Hu S, Parmet Y, Allen G, Parker DF, Ma F, Rouhani P, Kirsner RS. Disparity in melanoma: a trend analysis of melanoma incidence and stage at diagnosis among whites, Hispanics, and blacks in Florida. Arch Dermatol 2009; 145: 1369-1374.

16 Rouhani P, Pinheiro PS, Sherman R, Arheart K, Fleming LE, Mackinnon $\mathrm{J}$ et al. Increasing rates of melanoma among nonwhites in Florida compared with the United States. Arch Dermatol 2010; 146: 741-746. 